\title{
Implementasi Metode Qira'ati dalam Pembelajaran Ilmu Tajwid
}

\author{
Nur Ainun ${ }^{1}$, Ahmad Kosasih ${ }^{2}$ \\ ainunnur1202@gmail.com ${ }^{1}$, ahmadkosasihtanjung@gmail.com² \\ Universitas Negeri Padang1,2
}

\begin{tabular}{l}
\hline ARTICLE INFO \\
\hline Article history:
\end{tabular}

Received, 21 Oktober 2021

Revised, 10 November

2021

Accepted, 30 November 2021

\section{Keywords:}

Implementasi, Metode

Qira'ati, Ilmu Tajwid

\begin{abstract}
Penelitian ini bertujuan untuk mengetahui implementasi metode qira'ati dalam pembelajran ilmu tajwid di TPQ Muhammadiyah Sontang. Jenis penelitian yang digunakan adalah penelitian lapangan dan metode yang dipakai adalah metode kualitataif dengan pendekatan deskriptif. Hasil penelitian ini menjelaskan bahwa implementasi metode qira'ati dalam pembelajaran ilmu tajwid di TPQ Muhammadiyah Sontang adalah metode membaca Alquran yang langsung memasukkan dan mempraktekkan bacaan tartil sesuai dengan kaidah ilmu tajwid yang baik dan benar, tidak mengeja, akan tetapi langsung membaca bunyi huruf yang ada pada Alquran. Faktor penghambat dalam mengimplementasikan metode qira'ati antara lain tidak adanya motivasi dari guru itu sendiri sehingga menyebabkan kurangnya semangat dalam menerapkan metode tersebut, ketidak seriusan santri dalam belajar ilmu tajwid, kurang memadainya sarana dan prasaran di TPQ Muhammadiyah sontang. Faktor pendukung dalam mengimplementsikan metode qira'ati adalah tergantung pada niat santri itu sendiri, dukungan dari keluarga khususnya orang tua serta adanya dukungan dari pihak TPQ seperti kepala dan pengurus TPQ.
\end{abstract}

Corresponding Author: Nur Ainun, Department Islamic Education Faculty of Social Science Universitas Negeri Padang, Indonesia, Email: ainunnur1202@gmail.com Phone: $+6281360040665$

\section{Pendahuluan}

Para ulama mendefenisikan arti dari tajwid yaitu memberikan huruf akan hak-hak dan tertibnya, mengembalikan huruf kepada makhraj dan sifatnya serta menghaluskan pengucapannya dengan cara yang sempurna tanpa berlebih-lebihan, tergesa-gesa dan dipaksakan (Fahmi, 2008). Pengertian ilmu tajwid ialah ilmu yang digunakan untuk mengetahui dan memahami bagaimana cara me-lafadzkan atau mengucapakan huruf-huruf pada ayat Alquran dengan baik dan benar sesuai makhraj dan sifatnya. (Manna Khalil, 2007).

Sebagaimana dalam Alquran yang menganjurkan umat manusia membaca Alquran dengan baik dan benar, terdapat pada Q.S. Al-Muzzammil: 4

Artinya: "Atau lebih dari (seperdua) itu dan bacalah Alquran itu dengan perlahan-lahan."

Ayat di atas menjelaskan bahwa dalam membaca Alquran harus perlahan-lahan agar hatihati dan terhindar dari kesalahan membaca, membaca Alquran juga harus menggunakan ilmu 
tajwid agar tahu hukum-hukum yang ada tidak asal baca saja. Karena sedikit kesalahan akan mengakibatkan salah arti dari ayat yang dibaca. Tartil artinya membaca Alquran dengan cara perlahan-lahan, tidak terburu-buru, dengan bacaan yang baik dan benar sesuai dengan makhraj dan sifat-sifatnya sebagaimana yang dijelaskan dalam ilmu tajwid. (Majid, 2011: 41)

Manfaat memperlajari ilmu tajwid yaitu menjaga lidah dari kesalahan membaca Alquran, memudahkan dalam memahami makna maupun kalimat dalam ayat yang dibaca, memberikan keterangan dalam hukum-hukum bacaan yang ada pada ayat Alquran serta dicintai oleh Allah SWT. Oleh sebab itu, tajwid termasuk ilmu yang berkedudukan tinggi karena berkaitan erat dengan firman Allah Swt. (Imam Masyhadi, 2007). Mempelajari ilmu tajwid dari aspek teoritis adalah fardu kifayah. Sedangkan hukum menerapkan tajwid dari aspek praktik adalah fardu 'ain bagi setiap orang yang membaca Alquran. Membaca Alquran dengan tajwid hukumnya adalah fardu 'ain bagi setiap muslim.

Penentuan suatu metode pembelajaran Alquran ini penting, sehingga peneliti memilih tempat penelitian disuatu lembaga Taman Pendidikan Alquran Muhammadiyah Sontang yang mana di Taman Pendidikan Alquran ini sistem pembelajarannya menggunakan metode Qiroati. Tujuan dari penggunaan metode Qiroati tersebut ini adalah agar dapat mempermudah dan mempercepat cara belajar membaca Alquran pada anak.

Metode Qiroati merupakan salah satu metode dalam pembelajaran membaca Alquran yang mana metode ini lebih menekankan pada pendekatan keterampilan proses membaca secara cepat dan tepat, baik pada makhorijul hurufnya maupun bacaan tajwidnya, sehingga akan diperoleh hasil pengajaran yang efektif tahan lama dan dapat dikembangkan sesuai dengan kondisi kemampuan anak didik. |Dari observasi awal di TPQ Muhammadiyah Sontang kecamatan Padang Gelugur Kab. Pasaman Timur Provinsi Sumatera Barat yang peneliti lakukan pada tanggal 10 Desember-21 Desember 2020 terdapat bahwa pembelajaran ilmu tajwid belum optimal. Hal ini disebabkan oleh implementasi metode dalam mengajarkan atau meningkatkan pemahaman tentang ilmu tajwid belum tepat. Antara lain:

1. Guru TPQ hanya mengajarkan tajwid 1 kali dalam seminggu sehingga membuat para siswa akan mudah lupa tentang apa yang sudah diajarkan

2. Guru TPQ hanya mempraktekkan langsung kedalam Alqurancontoh hukum tajwid itu cuma satu kali dalam seminggu yaitu malam sabtu.

Akibatnya, pemahaman siswa mengenai ilmu tajwid yang di praktekkan langsung dengan membaca Alquran masih dangkal. Dalam pelaksannan pembelajaran ilmu tajwid, banyak siswa yang tidak memperhatikan misalnya ada yang mengobrol, main-main bahkan ada juga yang tertidur, kurang nya keseriusan perhatian siswa terhadap ilmu tajwid dalam membaca Alquran. Masalah tersebut dapat memperlambat siswa untuk dapat membaca Alquran dengan fasih.

\section{Tinjauan Pustaka}

\section{A. Ilmu Tajwid}

Pembelajaran pada dasarnya merupakan suatu system intruksional yang megacu pada pengertian sebagai seperangkat komponen yang saling bergantungan satu sama lainnya untuk mencapai tujuan yang diinginkan. Suatu system pembelajaran meliputi komponen, antara lain tujuan, bahan, siswa, guru, metode, sitiasi, dan evaluasi. (Syaiful Bahri Djamarah, 2015. Hlm 10-11)

Pengertian di atas dapat dipahami, yang dimaksud dengan pembelajaran adalah suatu aktivitas atau proses yang mengarahkan siswa melakukan proses belajar, dengan melibatkan unsur-unsur manusiawi, material, fasilitas, perlengkapan, dan prosedur yang saling mempengaruhi untuk mencapai tujuan pembelajaran. Pembelajaran Alquran adalah proses perubahan tingkah laku peserta didik melalui proses belajar, mengajar, membimbing, dan melatih peserta didik untuk membaca Alquran dengan fasih dan benar sesuai kaidah Ilmu tajwid agar peserta didik terbiasa belajar membaca Alquran dalam kehidupan sehari-hari. Membaca Alquran merupakan perbuatan ibadah yang 
Nur Ainun Dan Ahmad Kosasih : Implementasi Metode Qira'ati dalam Pembelajaran Ilmu...

berhubungan dengan Allah SWT, dengan membaca manusia akan memahami nilai-nilai yang terkandung dalam Alquran.

Tajwid menurut bahasa artinya al-tahsin atau memperbaiki, dalam arti yang lain menurut lughoh. Secara bahasa tajwid berarti al-tahsin atau dengan kata lain arti nya memperindah. Pengertian tajwid menurut para ulama ialahbahwa tajwid merupakan menyerahkan kepada huruf akan hak-hak dan tertibnya, serta memberikan huruf tersebut kepada makhraj dan sifatnya dan juga memperhalus pengucapan dengan cara yang sempurnna dengan tidak berlebihan, kasar, bergegas dan dipaksakan. (Fahmi, 2008). Pengertian tajwid menurut istilah, memiliki beberapa defenisi yang makna nya salung berdekatan, di antaranya :

1) Ilmu yang menjelaskan tentang hukum bacaan serta petunjuk yang harus dipatuhi ketika membaca Alquran dengan menyesuaikan metode yang diperoleh dari Rasulullah Saw.

2) Ilmu yang digunakan agar memahamiaturan ataucara pengucapan ayat-ayat Alquran. (Muhammad Isham, 2015)

Dengan demikian ilmu tajwid merupakan ilmu yang menjelaskan tata cara membaca Alquran dengan baik dan benar, serta cara memulai dan berhentinya (tempat-tempat ibtida' dan waqf-nya) dan hal lain yang berkaitan dengan itu.(Muhammad Hasbi, 2002).

1. Metode Pembelajaran Ilmu Tajwid

Setiap metode di kembangkan sesuai dengan ciri-cirinya. Metode-metode tersebut adalah sebagai berikut:

a. Metode Jibril, Metode Jibril ini di latarbrelakangi perintah Allah SWT kepada Nabi Muhammad SAW yaitu dengan cara mengikuti bacaan Alquran yang telah dibacakan oleh malaikat Jibril, sebagai penyampai wahyu

b. Metode Talaqqi

Metode talaqqi ialah cara yang digunakan oleh seorang guru dalam mengajarkan siswanya dengan cara berhadapan secara langsung dengan guru untuk mempelajari bacaan secara menyeluruh yang diawali dari Al-Fatihah sampai An-Nas secara berurutan.

c. Metode Qira'ati

Metode Qira'ati ini di tempuh dalam proses pembelajaran dengan pendekatan yaitu metode penyampaian secara langsung (ceramah), metode dengan mempraktekkan atau mengadakan latihan, mengulang atau menirukan (musyafahah), metode sintetik (tarkibiyyah), dan metode suara (bunyi). Metode qira'ati ini memiliki beberapa ciri-ciri antara lain pembelajarannya secara klasikal indifidu, siswa membaca secara langsung tanpa mengeja huruf, modul, tersusun secara terstruktur, bervariasi serta kreatif. (Baharuddin, 2012)

d. Metode Yanbu'a

Metode Ynabu'a merupakan suatu metode baca tulis dan menghafal Alquran, untuk membacanya siswa tidak boleh mengeja membaca langsung dengan cepat, tepat, lancar dan tidak putus-putus disesuaikan dengan kaidah makhorijul huruf.

e. Metode Asy-Syafi'i

Metode ini merupakan cara yang bisa diakatan mudah dalam memahami Alquran dalam bentuk buku. Metode Asy-syafi'i bersifat mandiri atau individual dalam proses pembelajaran, dengan kata lain guru sudah menyediakan bahan yang akan dipelajari sesuai dengan kurikulum yang telah ditetapkan yang dapat memudahkan siswa dalam pembelajaran.

2. Manfaat dan Hukum Mempelajari Ilmu Tajwid

a. Bagi yang mempelajari ilmu tajwid maka akan mendapatkan pahala serta dicintai oleh Allah SWT.

b. Bacaan Alquran akan lebih sempurna ketika kita sudah memahami ilmu tajwid dilihat dari pengucapan huruf, sifat-sifat seerta kaidah-kaidah tajwid. 
c. Akan memudahkan kita dalam memahami kalimat serta makna yang terkandung didalam ayat yang dibaca.

d. Memberikan keterangan dari hukum-hukum bacaan yang ada pada ayat Alquran. (Imam Masyhadi, 2007)

e. Menjaga dan menuntun lidah agar tidak terjadi kesalahan dalam pengucapan ayat Alquran.

Dengan demikian ilmu tajwid merupakan ilmu yang mempelajari tentang cara membaca Alquran dengan tepat, yakni mengetahui dimana harus berhenti dan memulai bacaan kembali "ibtida" serta mengetahui tempat keluarnya asal bunyi huruf "makhraj" hingga menyesuaikan sifat konseskuensi huruf tersebut. (Ahmad Sham, 2008).

Dengan adanya ilmu tajwid maka akan memudahkan serta menjaga lidah agar mengeluarkan bunyi huruf yang sesuai dengan kaidahnya dan bunyi makhrajnya serta menunaikan shifat lazimah dan shifat 'aridhah yang menjadi haqdan mustahaqnya. (Muhammad Isham, 2015)

\section{B. Implementasi Metode Qira'ati}

Implementasi adalah suatu penerapan, ide, konsep, kebijakan atau inovasi dalam suatu tindakan praktis sehingga memberi dampak, baik berupa pengetahuan, ketrampilan maupun nilai dan sikap. Menurut peneliti implementasi adalah tindakan atau pelaksanaan yang dilkukan seseorang dalam menentukan hasil yang diinginkan. Dapat juga di artikan tindakan yang dilakukan seseorang atau lebih karena terdapat mekanisme pada suatu sistem sehingga lebih terarah.

Metode Qira'ati adalah suatu metode dalam belajar membaca Alquran yang langsung memasukkan dan mempraktekkan bacaan tartil sesuai dengan kaidah ilmu tajwid. Jadi, implementasi metode qira'ati adalah penerapan suatu sistem yang dijalankan untuk mencapai tujuan dalam membaca Alquran dengan benra sesuai dengan ilmu tajwid. Tujuan dari pembelajaran membaca Alquran dengan metode qira'ati adalah meningkatkan kualitas pendidikan atau pengajaran Alquran dengan menyebarluaskan ilmu membaca Alqurandengan baik dan benar sesuai kaidah ilmu tajwid seperti yang telah dicontohkan Rasulallah SAW.

Sistem yang digunakan dalam pengajaran membaca Alquran dengan menggunakan Metode Qiroati yaitu :

a. diawali dengan membaca huruf-huruf hijaiyyah yang sudah berharakat secara langsung tanpa mengeja;

b. langsung praktik secara mudah dan praktis bacaan secara baik dan benar;

c. materi diberikan secara bertahap dan berkesinambungan (saling terkait satu sama lainnya);

d. materi pelajaran disusun sedemikian rupa sehingga anak-anak tidak akan mengalami kesulitan dalam belajar yaitu disusun dari yang mudah kemudian menuju ke yang sulit;

e. menerapkan belajar dengan cara system modul/paket;

f. menekankan pada banyak latihan membaca;

g. belajar sesuai dengan kesiapan dan kemampuan murid; dan

h. evaluasi dilakukan setiap hari(Munir, 2007: 32).

\section{Metode}

Penulis memilih jenis penelitian kualitatif lapangan (field research), yaitu dengan terjun langsung ke tempat penelitian di TPQ Muhammadiyah Sontang untuk mengetahui bagaimana implementasi metode qira'ati dalam pembelajaran ilmu tajwid kepda sntri. Dalam penelitian ini metode yang diterpakan oleh penulis yaitu metode penelitian kaulitatif. Penelitian kualitatif adalah suatu kegiatan yang dilakukan untuk menemukan, mengumpulkan, serta menganalisis data komprehensif agar memperoleh pengetahuan mengenai suatu kejadian atau fenomena yang dapat menarik perhatian. (Yusuf, 2014: 330).

Lokasi penelitian ini adalah di TPQ Muhammadiyah Sontang yang terletak di Jorong Murni Sontang, Kecamatan Padang Gelugur Kabupaten Pasaman Provinsi Sumatera Barat. 
Nur Ainun Dan Ahmad Kosasih : Implementasi Metode Qira'ati dalam Pembelajaran Ilmu...

Informan dalam penelitian ini adalah kepala TPQ, guru, sert santri di TPQ Muhammadiyah Sontang. Instrumen penelitian yang penulis gunakan adalah: seperti pedoman wawancara, kamera untuk mengambil dokumentasi berupa foto, buku catatan penting lainnya yang diperlukan dalam penelitian sebagai instrumen pendukung dalam penulisan. Dalam penelitian ini teknik pengumpulan data yang digunakan adalah observasi, wawancara, dan dokumentasi. Teknik penganalisisan data yang digunakan yaitu reduksi data, penyajian data, penarikan kesimpulan dan verifikasi. Teknik pengabsahan yang digunakan dalam penelitian ini yaitu dengan menggunakan teknik triangulasi sumber. Teknik triangulasi sumber yaitu: mengecek data yang telah diperoleh melalui beberapa sumber.

\section{Hasil dan pembahasan}

Dalam pelaksanaan kegiatan pembelajaran ilmu tajwid setelah menerapkan metode guru yaitu dengan menggunakan metode qira'ati, terdiri atas beberapa langkah-langkah kegiatan. Pertama, kegiatan pendahuluan terdiri atas pemberian arahan kepada santri untuk merapikan tempat duduk masing-masing, kemudian menunjuk salah seorang santri untuk memimpin doa secara bersama-sama, guru mengambil absen kehadiran dengan menyebut nama santri secara bergantian dan diakhiri dengan menanyakan kesiapan santri untuk mengikuti pembelajaran Alquran.

Kedua, kegiatan inti yakni, guru menulis di papan tulis tentang teori ilmu tajwid dan kemudian menjelaskan nya secara terperinci, guru akan membacakan teori yang dipapan tulis dan diikuti oleh semua santri secara bersamaan, setelah santri faham selanjutnya guru memanggil santri kedepan untuk membaca Alquran sekaligus menentukan ilmu tajwid yang terdapat pada ayat yang dibaca, guru akan memperbaiki kesalahan dalam membaca Alquran serta penentuan ilmu tajwid.

Ketiga, kegiatan penutup yakni, memberikan motivasi kepada santri untuk mengulangulang pembelajaran ilmu tajwid dirumah, guru memberikan tugas untuk dikerjakan dirumah tujuannya supaya santri lebih sering berlatih dan tidak mudah lupa, beroda bersama-sama diakhir sebagai tanda bahwa pembelajaran sudah selesai, kemudia santri bersalaman dengan guru secara teratur sebelum meninggalkan kelas.

Dalam proses pelaksanaan pembelajaran Alquran di TPQ Muhammadiyah Sontang dilaksanakan setiap hari ba'da Maghrib mulai malam Senin sampai malam Sabtu dengan jadwal dari jam 06.45 - 08.30 dengan rincian kegiatan setiap malamnya antara lain pada hari senin sampai kamis yaitu membaca Alquran secara bergantian, pada hari jumat melakukan kegiatan praktek sholat, dan pada hari sabtu belajar ilmu tajwid

Menurut peneliti pada proses pelaksanaan pembelajaran Alquran di TPQ Muhammadiyah Sontang, guru harus lebih bisa menguasai kelas dengan baik supaya santri juga lebih fokus kepada guru yang menjelaskan materi, karena apabila guru hanya fokus menjelaskan materi tanpa menghiraukan santrinya yang berkeliaran maka ini akan mengakibatkan rendah nya pemahaman santri atau bahkan tidak mengerti sama sekali terhadapa materi yang guru jelaskan. Maka dengan itu, seharusnya guru melakukan proses pembelajaran itu dengan tetap memperhatikan santrinya.

Sebagai upaya untuk meningkatkan pemahaman santri tentang pembelajaran Alquran khusus nya ilmu tajwid di TPQ Muhammadiyah Sontang, selain harus lebih bisa menguasai kelas dengan baik, guru juga hendaklah menggunakan sebuah strategi atau menerapkan metode dalam mengajar, karena akan berpengaruh terhadap santri dalam memahami materi ilmu tajwid.

Dengan demikian dapat peneliti simpulkan bahwa metode qira'ati yaitu proses pembelajaran yang teratur secara sistematis dalam rangka mengembangkan kemampuan membaca Alquran sesuai dengan kaidah hukum tajwid yang benar.

Pada pelaksanaan implementasi metode qira'ati dalam pembelajaran ilmu tajwid yang diterapkan di TPQ Muhammadiyah Sontang sudah bagus dan cocok di terapkan dalam pembelajaran Alquran karena memberikan kemudahan santri dalam membaca Alquran 
dengan tepat. Implementasi metode qira'ati dalam pembelajaran ilmu tajwid di TPQ Muhammadiyah Sontang yaitu metode membaca Alquran yang langsung memasukkan dan mempraktekkan bacaan tartil sesuai dengan kaidah ilmu tajwid yang baik dan benar, tidak mengeja, akan tetapi langsung membaca bunyi huruf yang ada pada Alquran.

Dengan menggunakan metode qira'ati dalam pembelajaran ilmu tajwid membuat santri di TPQ Muhammadiyah Sontang merasa senang dan juga mereka mudah memahami ilmu tajwid tersebut karena dipraktekkan langsung setelah guru menjelaskan. Alasan santri juga menyukai metode ini karena guru juga mengajarkan kami ilmu tajwid itu setiap malam membaca Alquran di kelas tanpa harus menunggu malam sabtu. Dengan demikian santri akan mudah memahami dan mengingat kembali teori ilmu tajwid itu dengan mudah.

Kelebihan dan kekurangan metode qira'ati antara lain meskipun siswa belum mengenal ilmu tajwid namun sudah bisa membaca Alquran secara tajwid, dalam metode qira'ati ini terdiri dari prinsip untuk guru dan murid, setelah khatam, maka santri akan meneruskan lagi bacaan ghorib, dan apabila santri sudah lulus 6 jilid beserta ghoribnya, maka di tes bacannya kemudian mendapa syahadah jika lulus tes. Kekurangan metode Qira'ati yaitu bagi santri yang tidak lancar maka lulusnya juga akan lama karena metode ini lulus itu tidak ditentukan oleh bulan atau tahun, melainkan tergantung kepada kemampuan membaca santri itu sendiri.

\section{Simpulan}

Pembelajaran ilmu tajwid di TPQ Muhammadiyah Sontang yang dilaksanakan hanya satu kali dalam seminggu mengkibatkan santri sulit untuk memahami ilmu tajwid dengan benar. Hal lain yang menyebakan santri sulit untuk memahami ilmu tajwid karena pembelajaran ilmu tajwid itu sendiri dipraktekkan langsung kedalam ayat Alquran hanya terfokus pada satu malam saja yaitu malam sabtu dan juga guru kurang menguasai keadaan kelas.

Metode yang digunakan guru saat pembelajaran ilmu tajwid di TPQ Muhammadiyah Sontang yaitu dengan menggunakan metode qira'ati. Metode ini dikatakan sudah berhasil diterapkan dalam pembelajaran ilmu tajwid, terlihat dari tingkat pemahaman santri tentang ilmu tajwid sudah meningkat dari yang sebelumnya. Contohnya ketika santri membaca Alquran yang langsung memasukkan bacaan tartil sudah sesuai dengan kaidah ilmu tajwid yang baik dan benar.

Faktor yang menjadi penghambat guru dalam mengimplementasikan metode qira'ati dalam pembelajaran ilmu tajwid antara lain : tidak adanya motivasi guru dalam diri sendiri sehingga menyebabkan kurangnya semangat dalam belajar, kurangnya motivasi atau dukungan dari orang tua santri, ketidakseriusan santri dalam belajar ilmu tajwid, adanya santri yang mengobrol dengan teman saat pembelajaran sedang berlangsung, serta kurang memadainya sarana dan prasarana.

Kemudian faktor pendukung atau pendorong guru dalam mengimplementasikan metode qira'ati dalam pembelajaran ilmu tajwid di TQP Muhammadiyah Sontang ialah kemauan santri dalam belajar tergantung pada niat nya sendiri, adanya dukungan dari keluarga santri yang menyebabkan santri semangat dalam belajaar ilmu tajwid, serta adanya dukungan yang diberikan oleh kepala dan pengurus TPQ untuk mewujudkan TPQ yang qur'ani.

\section{Referensi}

Ahmad Shams Madyan. 2008. Peta Pembelajaran Alquran. Yogyakarta: Pustaka Pelajar.

Baharuddin, "Metode Pembelajaran Ilmu Tajwid dalam Meningkatkan Kemampuan MembacaAlquran Santri Pondok Pesantren Tahfizh Alquran Al-Imam „Ashim”, (Skripsi Universitas Islam Negeri (UIN)Alauddin Makassar, 2012), p. 17

Imam Masyhadi. 2007. Pembimbing Ke Arah Kesempurnan Ilmu Tajwid, Jamiyatul Qurro' Wal Huffadz Wilayah Jawa Timur

Imam Masyhadi. 2007. Pembimbing Ke Arah Kesempurnan Ilmu Tajwid, Jamiyatul Qurro' Wal Huffadz Wilayah Jawa Timur

Majid, Abdul. 2011. Praktikum Qira'at (Keanehan Bacaan Alquran Qira'at Ashim dari Hafasah), Jakarta: Bumi Aksara 
Nur Ainun Dan Ahmad Kosasih : Implementasi Metode Qira'ati dalam Pembelajaran Ilmu...

Manna Khalil Al-Qattan. 2007. Studi Ilmu-Ilmu Alquran. Bogor: Litera Antar Nusa

Muhammad Isham. Muflih Al-Qudhat. 2015. Panduan Lengkap Ilmu Tajwid. Jakarta Selatan: Turos Pustaka.

Saiful Bahri Djamarah, Guru dan Anak Didik Dalam Interaksi Edukatif, Jakarta: PT. Rieneka Cipta, 2005, hal. 95

Yusuf, Muri. 2014. Metode Penelitian Kuantitatif, Kualitatif, dan Penelitian Gabungan, Jakarta: Prenadamedia Group 